\title{
On the fatigue-critical amplitude of random-amplitude stress
}

\author{
Janusz Kolenda \\ Gdańsk University of Technology \\ Polish Naval University
}

\section{ABSTRACT}

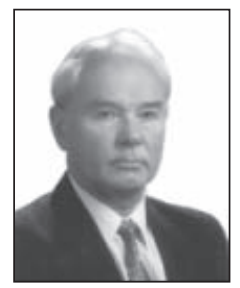

Uniaxial non-zero mean stress of constant circular frequency in the high-cycle fatigue regime is considered. It is assumed that equation of the $S-N$ curve and modified Soderberg equation are applicable. For constant-amplitude stress, the fatigue-critical stress amplitude is defined as that which leads to failure during the required design life. For random-amplitude stress, expected values of the fatigue-critical stress amplitude and total fatigue damage accumulated during the required design life are estimated. It is found that the probability of fatigue failure is equal to the probability of exceedance of the fatiguecritical stress amplitude. As an example, for stationary random stress the equivalent random-amplitude stress and probability of fatigue failure are determined.

Key words : uniaxial load, random stress, high-cycle fatigue, failure probability

\section{INTRODUCTION}

If a metallic element is subjected to asymmetric tensile-compressive stress

$$
\tilde{\sigma}(\mathrm{t})=\sigma_{0}+\sigma_{\mathrm{a}} \sin \omega \mathrm{t}
$$

in the high-cycle fatigue regime the following equations are frequently applied $[1,2]$

$$
\begin{gathered}
N \sigma^{\mathrm{m}}=\mathrm{K} \\
\sigma_{\mathrm{a}}=\sigma\left(1-\frac{\sigma_{0}}{\mathrm{R}_{\mathrm{e}}}\right) \quad, \quad \mathrm{Z}_{\mathrm{rc}}<\sigma \leq \mathrm{L}
\end{gathered}
$$$$
\text { where : }
$$

$\mathrm{K}$ - fatigue strength coefficient

L - maximum stress amplitude satisfying Eq. (2) (above which low-cycle fatigue may occur)

$\mathrm{m}$ - fatigue strength exponent

$\mathrm{N}$ - number of cycles to cause fatigue failure

$\mathrm{R}$ - tensile yield strength

$\mathrm{Z}_{\mathrm{rc}}^{\mathrm{e}}$ - fatigue limit under fully reversed tension-compression

$\sigma$ - amplitude of the fully reversed stress at a given number, $\mathrm{N}$, of cycles to cause failure

$\sigma_{\mathrm{a}}$ - amplitude of the stress (1) which will give that fatigue life

$\sigma_{0}-$ mean stress

$\omega$ - circular frequency.

If $\mathrm{N}_{\mathrm{d}}$ denotes the required cycle number the design criterion $\mathrm{N}_{\mathrm{d}}<\mathrm{N}$ becomes :

$$
\frac{\mathrm{N}_{\mathrm{d}}}{\mathrm{K}}\left(\frac{\sigma_{\mathrm{a}}}{1-\frac{\sigma_{0}}{\mathrm{R}_{\mathrm{e}}}}\right)^{\mathrm{m}}<1
$$

$$
\begin{aligned}
& \text { for: } \\
& \mathrm{Z}_{\mathrm{rc}}\left(1-\frac{\sigma_{0}}{\mathrm{R}_{\mathrm{e}}}\right)<\sigma_{\mathrm{a}} \leq \mathrm{L}\left(1-\frac{\sigma_{0}}{\mathrm{R}_{\mathrm{e}}}\right)
\end{aligned}
$$

Hence the stress amplitude $\sigma_{\text {cr }}$ that leads to fatigue failure in $\mathrm{N}_{\mathrm{d}}$ cycles is :

$$
\sigma_{\mathrm{cr}}=\left(1-\frac{\sigma_{0}}{\mathrm{R}_{\mathrm{e}}}\right)\left(\frac{\mathrm{K}}{\mathrm{N}_{\mathrm{d}}}\right)^{1 / \mathrm{m}}
$$

This quantity will be called the fatigue-critical stress amplitude.

\section{DESIGN CRITERION AT STATIONARY RANDOM-AMPLITUDE STRESS}

Let us determine the design criterion corresponding to Eq. (4) in the case of uniaxial Gaussian stress :

$$
\tilde{\sigma}_{x}(t)=\sigma_{0}+\sigma_{x} \sin (\omega t+\alpha)
$$

with the random amplitude $\sigma_{\mathrm{x}}$ and random phase angle $\alpha$. As to the stress amplitude it follows Rayleigh distribution [3] :

$$
\mathrm{F}\left(\sigma_{\mathrm{x}}\right)=1-\exp \left(-\frac{\sigma_{\mathrm{x}}^{2}}{2 \mathrm{~s}_{\mathrm{x}}^{2}}\right)
$$

where : $s_{x}$ is the standard deviation of the stress amplitude.

In terms of ensemble averages, the counterpart of the criterion (4) reads :

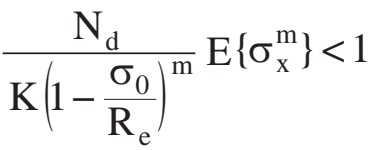

where : $\mathrm{E}\{\cdot\}$ denotes the expected value. In the considered case :

$$
\mathrm{E}\left\{\sigma_{\mathrm{x}}\right\}=(0.5 \pi)^{1 / 2} \mathrm{~s}_{\mathrm{X}}
$$




$$
\mathrm{E}\left\{\sigma_{\mathrm{x}}^{\mathrm{m}}\right\}=2^{\mathrm{m} / 2} \Gamma\left(1+\frac{\mathrm{m}}{2}\right) \mathrm{s}_{\mathrm{x}}^{\mathrm{m}}
$$

where : $\Gamma$ is the gamma function.

So, the criterion (8) becomes :

$$
\frac{2^{\mathrm{m} / 2} \mathrm{~N}_{\mathrm{d}}}{\mathrm{K}\left(1-\frac{\sigma_{0}}{\mathrm{R}_{\mathrm{e}}}\right)^{\mathrm{m}}} \Gamma\left(1+\frac{\mathrm{m}}{2}\right) \mathrm{s}_{\mathrm{x}}^{\mathrm{m}}<1
$$

for :

$$
\mathrm{Z}_{\mathrm{rc}}\left(1-\frac{\sigma_{0}}{\mathrm{R}_{\mathrm{e}}}\right)<(0.5 \pi)^{1 / 2} \mathrm{~s}_{\mathrm{x}} \leq \mathrm{L}\left(1-\frac{\sigma_{0}}{\mathrm{R}_{\mathrm{e}}}\right)
$$

\section{FATIGUE-CRITICAL STRESS AMPLITUDE AND PROBABILITY OF FATIGUE FAILURE UNDER STATIONARY RANDOM-AMPLITUDE STRESS}

$$
\begin{gathered}
\text { Eqs (9) and (11) yield : } \\
\frac{\mathrm{N}_{\mathrm{d}} \Gamma\left(1+\frac{\mathrm{m}}{2}\right)\left[\mathrm{E}\left\{\sigma_{\mathrm{x}}\right\}\right]^{\mathrm{m}}}{(0.25 \pi)^{\mathrm{m} / 2}\left(1-\frac{\sigma_{0}}{\mathrm{R}_{\mathrm{e}}}\right)^{\mathrm{m}} \mathrm{K}}<1
\end{gathered}
$$

Hence the expected value of the fatigue-critical amplitude of the stress (6) can be estimated as :

$$
\sigma_{\mathrm{cr}}=(0.25 \pi)^{1 / 2}\left(1-\frac{\sigma_{0}}{\mathrm{R}_{\mathrm{e}}}\right)\left[\frac{\mathrm{K}}{\mathrm{N}_{\mathrm{d}} \Gamma\left(1+\frac{\mathrm{m}}{2}\right)}\right]^{1 / \mathrm{m}}
$$

With the respect to the distribution function (7), the probability, $\mathrm{P}_{\mathrm{cr}}$, of exceedance of the fatigue-critical stress amplitude is given by :

$$
P_{c r}=P\left\{\sigma_{x} \geq \sigma_{c r}\right\}=\exp \left(-\frac{\sigma_{c r}^{2}}{2 s_{x}^{2}}\right)
$$

From Eqs (13) and (14) one obtains :

$$
\mathrm{P}_{\mathrm{cr}}=\exp \left\{-\frac{0.25 \pi}{2 \mathrm{~s}_{\mathrm{x}}^{2}}\left(1-\frac{\sigma_{0}}{\mathrm{R}_{\mathrm{e}}}\right)^{2}\left[\frac{\mathrm{K}}{\mathrm{N}_{\mathrm{d}} \Gamma\left(1+\frac{\mathrm{m}}{2}\right)}\right]^{2 / \mathrm{m}}\right\}
$$

Now, the task is to determine the relation between $\mathrm{P}_{\mathrm{cr}}$ and the probability, $\mathrm{P}_{\mathrm{f}}$, of fatigue failure under the stress (6). According to the Palmgren-Miner rule $[1,2]$ the increment of fatigue damage, caused by $\mathrm{N}_{\mathrm{d}}$ stress cycles of constant amplitude is equal to the ratio $\mathrm{N}_{\mathrm{d}} / \mathrm{N}$ where $\mathrm{N}$ is the cycle number to cause failure. Referring to the stress (6) the expected cycle number to failure can be estimated by means of Eq. (12) as :

$$
\mathrm{N}=\frac{(0.25 \pi)^{\mathrm{m} / 2}\left(1-\frac{\sigma_{0}}{\mathrm{R}_{\mathrm{e}}}\right)^{\mathrm{m}} \mathrm{K}}{\Gamma\left(1+\frac{\mathrm{m}}{2}\right)\left[\mathrm{E}\left\{\sigma_{\mathrm{x}}\right\}\right]^{\mathrm{m}}}
$$

Hence the expected value, D, of the fatigue damage after $\mathrm{N}_{\mathrm{d}}$ cycles is :

$$
\mathrm{D}=\frac{\mathrm{N}_{\mathrm{d}} \Gamma\left(1+\frac{\mathrm{m}}{2}\right)\left[\mathrm{E}\left\{\sigma_{\mathrm{x}}\right\}\right]^{\mathrm{m}}}{(0.25 \pi)^{\mathrm{m} / 2}\left(1-\frac{\sigma_{0}}{\mathrm{R}_{\mathrm{e}}}\right)^{\mathrm{m}} \mathrm{K}}
$$

and the probability of fatigue failure :

$$
\mathrm{P}_{\mathrm{f}}=\mathrm{P}\{\mathrm{D} \geq 1\}
$$

becomes :

$$
\begin{gathered}
P_{f}=P\left\{\sigma_{x} \geq(0.25 \pi)^{1 / 2}\left(1-\frac{\sigma_{0}}{R_{e}}\right)\left[\frac{K}{N_{d} \Gamma\left(1+\frac{m}{2}\right)}\right]^{1 / m}\right\}= \\
=P\left[\sigma_{x} \geq \sigma_{c r}\right]
\end{gathered}
$$

Hereby the following has been proved : In the high-cycle regime the probability of fatigue failure under random-amplitude stress is equal to the probability of exceedance of the fatigue-critical stress amplitude.

\section{EXAMPLE}

Let us consider a stationary random stress :

$$
\tilde{\sigma}_{\mathrm{x}}(\mathrm{t})=\sigma_{0}+\tilde{\sigma}_{\mathrm{r}}(\mathrm{t})
$$

where : $\sigma_{0}$ is the mean value of the stress $\tilde{\sigma}_{x}(t)$ and $\tilde{\sigma}_{r}(t)$ is the stationary (in the wide sense) stochastic process of zero mean value and known power spectral density $S(\omega)$. The suggestion is to model the stress $\tilde{\sigma}_{\mathrm{x}}(\mathrm{t})$ by the equivalent stress $\tilde{\sigma}_{e}(t)$ in the form of a periodic (in the mean-square sense [4]) Gaussian process :

$$
\begin{gathered}
\tilde{\sigma}_{e}(t)=\sigma_{e}+a \sin \left(\omega_{e} t+\varphi\right)= \\
=\sigma_{e}+a_{1} \exp \left(j \omega_{e} t\right)+a_{2} \exp \left(-j \omega_{e} t\right)
\end{gathered}
$$

where :

$\sigma_{\mathrm{e}}-$ the mean value of the stress $\tilde{\sigma}_{\mathrm{e}}(\mathrm{t})$

$\omega_{\mathrm{e}}-$ the circular frequency of the equivalent stress

a - the random amplitude of Rayleigh distribution

$\varphi$ - the random phase and :

$$
\begin{gathered}
a_{1}=\frac{a}{2 j} \exp (j \varphi), a_{2}=a_{1}^{*} \\
E\left\{a_{1}\right\}=E\left\{a_{2}\right\}=E\left\{a_{1} a_{2}^{*}\right\}=E\left\{a_{1}^{*} a_{2}\right\}=0 \\
(\cdot)^{*}-\text { complex conjugate } \\
j-\text { imaginary unity. }
\end{gathered}
$$

Following the approach based on the theory of energy transformation systems [5] and presented in [6], the equivalence conditions are :

$$
\begin{aligned}
\mathrm{E}\left\{\tilde{\sigma}_{\mathrm{e}}(\mathrm{t})\right\} & =\mathrm{E}\left\{\tilde{\sigma}_{\mathrm{x}}(\mathrm{t})\right\} \\
\mathrm{C}_{\widetilde{\sigma}_{\mathrm{e}}}(\tau) & =\mathrm{C}_{\widetilde{\sigma}_{\mathrm{x}}}(\tau) \\
\mathrm{C}_{\dot{\tilde{\sigma}}_{\mathrm{e}}}(\tau) & =\mathrm{C}_{\dot{\sigma}_{\mathrm{x}}}(\tau)
\end{aligned}
$$

where : $\mathrm{C}$ stands for the autocorrelation function, $\tau$ is the time interval, and dot denotes the time derivative. The results of calculation are as follows :

$$
\begin{gathered}
\sigma_{\mathrm{e}}=\sigma_{0} \\
\mathrm{~s}_{\mathrm{e}}=\left[\int_{-\omega}^{\infty} \mathrm{S}(\omega) \mathrm{d} \omega\right]^{1 / 2} \\
\omega_{\mathrm{e}}=\left[\frac{\left.\int_{-\infty}^{\infty} \omega^{2} \mathrm{~S}(\omega) \mathrm{d} \omega\right]^{1 / 2}}{\int_{-\omega}^{\infty} \mathrm{S}(\omega) \mathrm{d} \omega}\right]^{\infty}
\end{gathered}
$$

where : $\mathrm{s}$ is the standard deviation of the equivalent stress amplitude. 
By analogy with the stress (6) and Eq. (13), the expected value of the fatigue-critical amplitude of the equivalent stress is as follows :

$$
\mathrm{a}_{\mathrm{cr}}=(0.25 \pi)^{1 / 2}\left(1-\frac{\sigma_{0}}{\mathrm{R}_{\mathrm{e}}}\right)\left[\frac{2 \pi \mathrm{K}}{\omega_{\mathrm{e}} \mathrm{T}_{\mathrm{d}} \Gamma\left(1+\frac{\mathrm{m}}{2}\right)}\right]^{1 / \mathrm{m}}
$$

where : $T_{d}$ is the required design life (in seconds).

Consequently, when the following condition is met :

$$
\mathrm{Z}_{\mathrm{rc}}\left(1-\frac{\sigma_{0}}{\mathrm{R}_{\mathrm{e}}}\right)<(0.5 \pi)^{1 / 2} \mathrm{~s}_{\mathrm{e}} \leq \mathrm{L}\left(1-\frac{\sigma_{0}}{\mathrm{R}_{\mathrm{e}}}\right)
$$

the probability of fatigue failure during the time $T_{d}$ can be estimated as :

$$
\begin{gathered}
P_{f}=P\left\{a \geq a_{c r}\right\}=\exp \left(-\frac{a_{c r}^{2}}{2 s_{e}^{2}}\right) \\
\text { If : } \\
(0.5 \pi)^{1 / 2} s_{e}>L\left(1-\frac{\sigma_{0}}{R_{e}}\right)
\end{gathered}
$$

the low-cycle fatigue failure may occur.

In the case of :

$$
(0.5 \pi)^{1 / 2} \mathrm{~s}_{\mathrm{e}} \leq \mathrm{Z}_{\mathrm{rc}}\left(1-\frac{\sigma_{0}}{\mathrm{R}_{\mathrm{e}}}\right)
$$

an infinite fatigue life may be expected.

Its probability is considered in [6].

\section{CONCLUSIONS}

The deterministic and probabilistic fatigue-critical amplitudes of uniaxial asymmetric stresses are defined as those which lead to high-cycle fatigue failure during the required design life.

It is found that the probability of fatigue failure under random-amplitude stress is equal to the probability of exceedance of the fatigue-critical stress amplitude.

It is shown how the probability of fatigue failure under stationary random stress of known power spectral density can be estimated by means of the fatigue-critical amplitude of the equivalent random-amplitude stress.

\section{NOMENCLATURE}

a - amplitude of the equivalent stress

$\mathrm{a}_{\mathrm{cr}}$ - fatigue-critical amplitude of the equivalent stress

$\mathrm{C}$ - autocorrelation function

D - fatigue damage accumulated during the required design life

$E\{\cdot\}$ - expected value

$\mathrm{F}$ - distribution function

j - imaginary unity

$\mathrm{K}$ - fatigue strength coefficient

L - maximum stress amplitude satisfying equation of the S-N curve (above which low-cycle fatigue is possible)

$\mathrm{m}$ - fatigue strength exponent

$\mathrm{N}$ - number of stress cycles to cause fatigue failure

$\mathrm{N}_{\mathrm{d}}$ - required cycle number

$\mathrm{P}-$ probability

$\mathrm{P}_{\mathrm{cr}} \quad-$ probability of exceedance of the fatigue-critical stress amplitude

$\mathrm{P}_{\mathrm{f}} \quad-$ probability of fatigue failure

$\mathrm{R}_{\mathrm{e}} \quad-$ tensile yield strength

$\mathrm{S} \quad$ - power spectral density

$\mathrm{s}_{\mathrm{e}} \quad-$ standard deviation of the equivalent stress amplitude $\mathrm{s}_{\mathrm{x}} \quad$ - standard deviation of the stress amplitude

$\mathrm{t}-$ time

$Z_{\mathrm{rc}}$ - fatigue limit under fully reversed tension-compression

$\alpha \quad-$ phase angle of the stress (6)

$\Gamma \quad$ - gamma function

$\sigma \quad-$ amplitude of the fully reversed stress

$\tilde{\sigma}-$ asymmetric stress

$\sigma_{\mathrm{a}} \quad$ - amplitude of the stress (1)

$\sigma_{c r}^{a} \quad$ - fatigue-critical stress amplitude

$\sigma_{\mathrm{e}} \quad-$ equivalent mean stress

$\tilde{\sigma}_{\mathrm{e}}^{\mathrm{e}}-$ equivalent stress

$\sigma_{0}-$ mean stress

$\tilde{\sigma}_{\mathrm{r}}$ - stationary random stress of zero mean value

$\sigma_{\mathrm{x}} \quad$ - amplitude of the stress (6)

$\tilde{\sigma}_{\mathrm{x}}-$ asymmetric random-amplitude stress, asymmetric random stress

- time interval

- phase angle of the equivalent stress

- circular frequency

- circular frequency of the equivalent stress

)$^{*}$ - complex conjugate

\section{BIBLIOGRAPHY}

1. Kocańda S., Szala J.: Fundamentals of fatigue calculations (in Polish). PWN (State Scientific Publishing House). Warszawa. 1997

2. Almar-Naess A. (Ed.): Fatigue handbook. Offshore steel structures. Tapir Publishers. Trondheim. 1985

3. Pacut A.: Probability theory. Probabilistic modeling in technology (in Polish). WNT (Scientific - Technical Publishing House). Warszawa. 1985

4. Preumont A.: Vibrations aléatoires et analyse spectrale. Lausanne: Presses Polytechniques et Universitaires Romandes, CH-1015. 1990

5. Cempel C.: Theory of energy transformation systems and their application in diagnostic of operating systems. Applied Math. and Computer Sciences, No 2/1993

6. Kolenda J.: On fatigue safety of metallic elements under static and dynamic loads. Gdańsk University of Technology Publishers. 2004

\section{CONTACT WITH THE AUTHOR}

Prof. Janusz Kolenda

Faculty of Ocean Engineering and Ship Technology,

Gdańsk University of Technology

Narutowicza 11/12

80-952 Gdańsk, POLAND

e-mail : sek7oce@pg.gda.pl

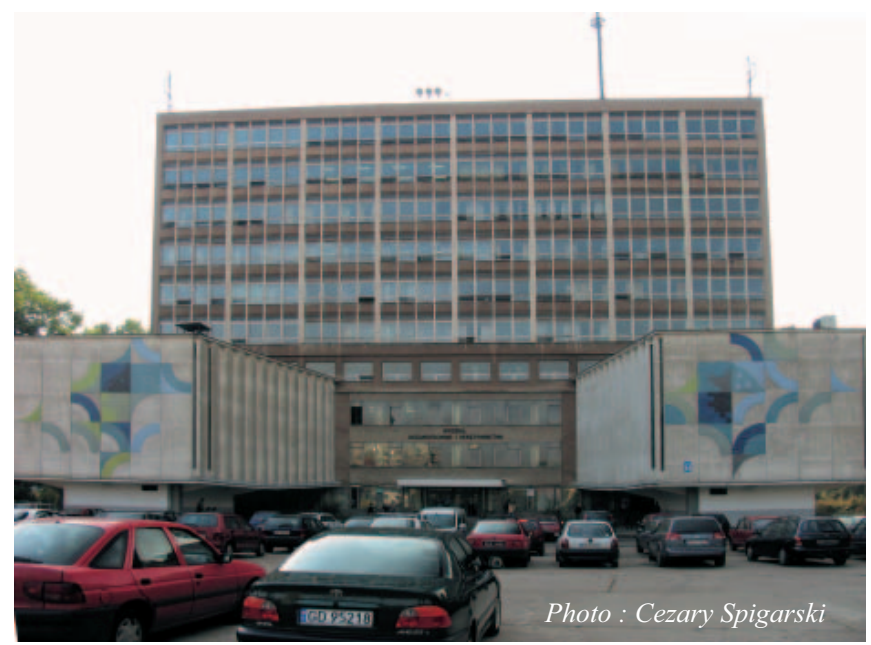

Main building of the Faculty of Ocean Engineering and Ship Technology, Gdańsk University of Technology 